\title{
Prevalence of MRSA and Biofilm Associated Gene among Clinical Isolates of Staphylococci
}

\author{
Pradha Velu, Ramya Rengaraj*, Usha Sekar and Saleem \\ Department of Microbiology, MAPIMS, Kancheepuram, Tamil Nadu, India \\ *Corresponding author
}

\begin{tabular}{|c|}
\hline Keywords \\
\hline $\begin{array}{l}\text { Staphylococcus, } \\
\text { MRSA, Bioflim, } \\
\text { mecA gene, CoNS }\end{array}$ \\
\hline Article Info \\
\hline $\begin{array}{l}\text { Accepted: } \\
\text { 06 December } 2017 \\
\text { Available Online: } \\
\text { 10 January } 2018\end{array}$ \\
\hline
\end{tabular}

\section{A B S T R A C T}

Staphylococcus spp is a major cause of nosocomial and community-acquired infections and represents a significant burden on the healthcare system. Establishment of a mature biofilm, play an important role in the persistence of chronic infections and also decreases the susceptibility to antimicrobials and immune defenses, making these infections difficult to eradicate. MRSA and MR-CONS has become a major public health problem in both hospitals and communities. PVL has been reported to be an important marker for the highly pathogenic community acquired $S$. aureus infections. A rapid detection of these MRSA is very important for its treatment. Hence, this study was done to determine the prevalence of mec $A$, fem $A$ and $p v l$ gene using triplex PCR and its relation to phenotypic and genotypic presence of biofilm formation. We collected 73 clinical isolates of Staphylococcus spp from the tertiary care center. AST was performed and interpreted according to CLSI guidelines 2017. TCP method was used to detect the biofilm formation. Cefoxitin disk method was performed for detection of methicillin resistant followed by triplex PCR for the detection of mec A, fem A and $p v l$ gene. A simplex PCR was done for detection biofilm encoding gene such as icaAD. Of the 73 isolates, 49 isolates were identified as $S$. aureus, 18 and 6 were $S$. epidermidis and S. saprophyticus respectively. The majority of the isolate was from pus and urine. By AST, highest resistance was observed for penicillin followed by erythromycin and co-trimoxazole. 51 isolates were considered as methicillin resistance by phenotypic method and by PCR. fem $A$ was seen in 49 isolates and $p v l$ was detected in 27 and 9 isolates of MRSA and MSSA respectively. 58 isolates were considered as strong biofilm producers and 15 were non-biofilm producers by TCP method. PCR detected icaAD in 31 isolates.

\section{Introduction}

Antibiotic resistance and biofilm-forming capacity of the Staphylococcus spp contribute as a major pathogen in both healthcare and community settings. Biofilms are defined as communities of bacteria encased in a self- synthesized extracellular polymeric matrix that attaches to a biotic or abiotic surface. Biofilm-forming staphylococci including $S$. aureus and $S$. epidermidis, have been one of the major cause of chronic polymer-associated infection. Infections involving biofilmforming bacteria are extremely difficult to 
eradicate because biofilms impair antibiotic penetration and prevent normal immune responses (Arciola et al., 2012). The expression of biofilm is mostly influenced by acquisition of the methicillin resistance gene $m e c A$. Biofilm formation in Staphylococci is encoded by ica ABCD operon and ica $A D$ is the most prevalent gene among biofilm forming Staphylococci.

femA is a chromosomally encoded ubiquitous gene, which is involved in the formation of the peptidoglycan pentaglycine interpeptide linkages. It can be used as a marker for the differentiation of $S$. aureus from the coagulase negative Staphylococci (Francois et al., 2003).

The presence of panton valentine leukocidin (PVL) toxin is the genotypic marker that differentiate community acquired methicillinresistant S. aureus (CA-MRSA) strains from hospital-acquired (HA)- MRSA.

The $S$. aureus isolates with $P V L$ are rapidly spreading and they cause serious skin and soft tissue infections such as pyomyositis, abscesses, breast abscesses, necrotizing fasciitis and pneumonia in otherwise healthy individuals (Gülmez et al., 2012).

It has been known that methicillin-resistant $S$. aureus (MRSA) cause many device-related infections and other chronic infections grow in biofilms or on these devices. Some studies have shown that it is very difficult to treat biofilm-forming staphylococcal infections with antibiotics.

Moreover, MRSA is the most common cause of nosocomial infections in intensive care units. However, the prevalence of CA-MRSA strains in healthcare settings is increasing. Here, we studied the biofilm-forming ability of MRSA and analyzed the relationship between phenotypic and their molecular detection in clinical isolates of $S$. aureus.

\section{Materials and Methods}

A total of 73 retrospective clinical isolates of Staphylococci were collected between June 2015to August 2016 from a tertiary care center in Kancheepuram, from various clinical specimens such as pus (65\%), urine $(25 \%)$ and blood $(10 \%)$. The isolates were identified by standard methods.

Antibiotic sensitivity testing was carried out by Kirby-Bauer disc diffusion method (Bauer et al., 1966) for the following antibiotics such as Penicillin (10 units), Clindamycin $(2 \mu \mathrm{g})$, Co-trimoxazole (1.25/23.75 $\mu \mathrm{g})$, Erythromycin $(15 \mu \mathrm{g})$, Tetracycline $(30 \mu \mathrm{g})$, Ciprofloxacin $(5 \mu \mathrm{g})$, Gentamicin $(10 \mu \mathrm{g})$, Vancomycin (30 $\mu \mathrm{g})$ and interpreted according to the CLSI 2017 guidelines. S. aureus ATCC 25923 was used as quality control.

\section{Screening for methicillin resistance (Cefoxitin disc diffusion)}

Cefoxitin disc (30 $\mu \mathrm{g}$ Hi Media Labs) was used for screening methicillin resistance. Sensitivity testing was done according to the standard disc diffusion method. Zone of inhibition was measured and interpreted according to CLSI guidelines (CLSI, 2017). $S$. aureus MRSA ATCC 43300 was used as quality control.

\section{Biofilm production by crystal violet method}

A liquid culture of the test isolate was adjusted to a turbidity of $0.5 \mathrm{McF}$ arland standard and diluted 1:100 in Trypticase Soy Broth (TSB) with $0.25 \%$ glucose and $200 \mu \mathrm{L}$ of this solution was incubated in 96 -well plates at $37^{\circ} \mathrm{C}$ for 24 hrs. Sterile broth was used as negative control. After incubation, the contents of the each well were removed by tapping. The wells were washed four times with $200 \mu \mathrm{L}$ of phosphate buffer saline $(\mathrm{pH} 7.2)$. The wells were fixed by $200 \mu \mathrm{L}$ of $2 \%$ sodium acetate and kept at 
room temperature for 30mins, then stained by $200 \mu \mathrm{L}$ of $0.1 \%$ crystal violet. Excess stain was removed by using sterile water and attached dye was solubilized with $95 \%$ ethanol and the optical density (OD) of the adherent biofilm was read at 570nm by using ELISA reader (Biotek Epoch). The experiment was performed in triplicate (Hassan et al., 2011). The isolates of biofilm production were categorized into non/Weak, moderate and strong producers (Table 1).

Optical density cut-off value $(\mathrm{ODc})=$ average OD of negative control $+3 x$ standard deviation (SD) of negative control.

\section{Molecular methods}

\section{DNA extraction- boiling lysis method}

DNA extraction was carried out by boiling lysis-method. In this method, pure discrete colonies from sheep blood agar were transferred into a microcentrifuge tube containing $1 \mathrm{ml}$ of LB broth and incubated overnight at $37^{\circ} \mathrm{C}$. Then it was centrifuged at $10,000 \mathrm{rpm}$ for 10 minutes in Remi cooling centrifuge. The pellets were washed in $1 \mathrm{~mL}$ TE buffer and centrifuged for another 2 minutes. The pellets were resuspended in 200 $\mu 1$ of DNase-free water (Qiagen, Germany) and the suspension was boiled at $100^{\circ} \mathrm{C}$ for $10 \mathrm{mins}$ in the dry bath. After boiling, the tube was kept overnight in the deep freezer $\left(-20^{\circ} \mathrm{C}\right)$ and then centrifuged at $10000 \mathrm{rpm}$ for 10 minutes. The supernatant which contained the extracted bacterial DNA was stored at $-20^{\circ} \mathrm{C}$ and used in the PCR assay.

\section{Detections of MRSA/ MRCoNS}

A Rapid multiplex PCR (femA, mecA and pvl) was performed forthe simultaneous detection and differentiation of MRSAand MR-CoNS (Abimanyuet al., 2013). PCR was carried out in a $25 \mu 1$ reaction mix containing $200 \mu \mathrm{M}$ of dNTPs, 1X PCR buffer (TrisHCl
$[10 \mathrm{mM}] ; \mathrm{KCl}[50 \mathrm{mM}] ; \mathrm{MgCl}_{2}$ [1.5mM] and $0.1 \mathrm{U}$ Taq DNA polymerase (New England Biolabs, Inc, U.K), primers (10pmol each) and 5 ng of template DNA. The details of the primers are given in table 1. Amplification was done using Mastercycler (Eppendorf, Hamburg, Germany) with the following cycling conditions: one cycle of initial denaturation at $94^{\circ} \mathrm{C}$ for $3 \mathrm{~min}, 30$ cycles of denaturation at $94^{\circ} \mathrm{C}$ for $30 \mathrm{~s}$, annealing for $30 \mathrm{~s}$ at $60^{\circ} \mathrm{C}$ and extension at $72^{\circ} \mathrm{C}$ for $30 \mathrm{~s}$ followed by a final extension at $72^{\circ} \mathrm{C}$ for 7 mins.

\section{Detection of biofilm-associated genes (icaAD)}

Biofilm-associated genes (icaAD) was amplified by simplex PCR method using primers such as $F$ : TAGTAATCACAGCCAACATCTT and R: AAACAAACTCATCCATCCGAAT which gives and amplicon size of 496bp (Araujo et al., 2006). S. epidermidis 35984 was used as positive control. PCR was carried out in a $25 \mu \mathrm{l}$ reaction mix containing $200 \mu \mathrm{M}$ of dNTPs, 1X PCR buffer (TrisHCl [10mM]; $\mathrm{KCl}[50 \mathrm{mM}] ; \mathrm{MgCl} 2$ [1.5mM] and 0.1U Taq DNA polymerase (New England Biolabs, Inc, U.K), primers (10pmol each) and 5ng of template DNA. Amplification was done using Master cycler (Eppendorf, Hamburg, Germany) with the following cycling conditions: one cycle of initial denaturation at $94^{\circ} \mathrm{C}$ for 4 mins, 30 cycles of denaturation at $94^{\circ} \mathrm{C}$ for $30 \mathrm{~s}$, annealing for $30 \mathrm{~s}$ at $55^{\circ} \mathrm{C}$ and extension at $72^{\circ} \mathrm{C}$ for $1 \mathrm{~min}$ followed by a final extension at $72^{\circ} \mathrm{C}$ for $5 \mathrm{mins}$.

\section{Results and Discussion}

Of 73 isolates, the majority of isolates were obtained from pus $(65 \%)$ followed by urine (25\%). By phenotypic method, 49 (67.1\%) isolates were identified as $S$. aureus and the remaining $24(33.8 \%)$ isolates were identified as $S$. epidermidis (18 isolates) and $S$. 
saprophyticus (6 isolates). Among 73 isolates, highest resistance was observed for penicillin $(\mathrm{n}=43,59 \%)$ followed by erythromycin $(\mathrm{n}=35$, $50 \%)$ and cotrimoxazole $(\mathrm{n}=35,50 \%)$ (Figure 1). All the isolates were found to be susceptible to gentamicin and vancomycin.

Out of 73 staphylococcal isolates, femA was amplified in $49(67 \%)$ isolates of $S$. aureus, whereas no amplification of $f e m A$ was seen in remaining 24 (32.8\%) isolates of $S$. epidermidis and $S$. saprophyticus. Triplex PCR detected mec $A$ in 36 (49.3\%) isolates of S. aureus; $13(17.8 \%)$ and $2(2.7 \%)$ isolates of $S$. epidermidis and $S$. saprophyticus respectively (Table 2 and Figure 2). Out of 36
MRSA isolates, 27 (75\%) were found to be positive for $p v l$ gene which showed the community associated MRSA and the remaining $9(25 \%)$ isolates were hospital associated MRSA. Among MSSA, 9/13 (69.2\%) were pvl positive, CA-MSSA.

Out of 73 isolates, $58(55.1 \%)$ isolates were considered as strong, $63(32.1 \%)$ isolates as moderate and $25(12.7 \%)$ isolates as nonbiofilm producers (Table 3). Simplex PCR of icaAD gene showed positive in $35 / 49$ (71.4\%), $10 / 18(55.5 \%)$ and $3 / 6(50 \%)$ isolates of $S$. aureus, S. epidermidis and S. Saprophyticus respectively (Figure 3).

Table.1 Detections of MRSA/ MRCoNS (Al-Talib et al., 2009)

\begin{tabular}{|c|c|c|}
\hline $\begin{array}{l}\text { Target } \\
\text { genes }\end{array}$ & Primer sequences $5^{\prime} \longrightarrow 3^{\prime}$ & Expected Amplicon size \\
\hline femA & $\begin{array}{l}\text { F: CGATCCATATTTACCATATCA } \\
\text { R: ATCACGCTCTTCGTTTAGTT }\end{array}$ & $450 \mathrm{bp}$ \\
\hline mecA & $\begin{array}{l}\text { F: ACGAGTAGATGCTCAATATAA } \\
\text { R: CTTAGTTCTTTAGCGATTGC }\end{array}$ & $293 \mathrm{bp}$ \\
\hline lukS (PVL) & $\begin{array}{l}\text { F: CAGGAGGTAATGGTTCATTT } \\
\text { R: ATGTCCAGACATTTTACCTAA }\end{array}$ & $151 \mathrm{bp}$ \\
\hline
\end{tabular}

Table.2 Distribution of mec $A$ and $p v l$ gene in isolates of Staphylococci

\begin{tabular}{|c|c|c|c|}
\hline Genes & $\begin{array}{c}\text { No. of isolates } \\
\text { showed positive } \\
\text { S. aureus }\end{array}$ & $\begin{array}{c}\text { No. of isolates } \\
\text { showed positive } \\
\text { S. epidermidis }\end{array}$ & $\begin{array}{c}\text { No. of isolates } \\
\text { showed positive } \\
\text { S. saprophyticus }\end{array}$ \\
\hline fem $A$ & $49(67 \%)$ & 0 & 0 \\
\hline mec $A$ & $36(49.3 \%)$ & $13(17.8 \%)$ & $2(2.7 \%)$ \\
\hline Total no. of isolates & $\mathbf{4 9}$ & $\mathbf{1 8}$ & $\mathbf{6}$ \\
\hline
\end{tabular}

Table.3 Distribution of biofilm formation in isolates of Staphylococci

\begin{tabular}{|c|c|c|c|}
\hline Biofilm formation & $\begin{array}{c}\text { No. of isolates } \\
\text { S.aureus }\end{array}$ & $\begin{array}{c}\text { No. of isolates } \\
\text { S. epidermidis }\end{array}$ & $\begin{array}{c}\text { No. of isolates } \\
\text { S. saprophyticus }\end{array}$ \\
\hline Strong & $42(85.7 \%)$ & $13(72.2 \%)$ & $3(50 \%)$ \\
\hline Moderate & $2(4 \%)$ & 0 & $2(33.3 \%)$ \\
\hline Non biofilm producers & $5(10 \%)$ & $5(27.7 \%)$ & $1(16.6 \%)$ \\
\hline Total & $\mathbf{4 9}$ & $\mathbf{1 8}$ & $\mathbf{6}$ \\
\hline
\end{tabular}


Fig.1 Antimicrobial susceptibility pattern of clinical isolates of Staphylococci. P- Penicillin; EErythromycin; CD- Clindamycin; COT-Cotrimoxazole; GEN- Gentamycin; TET-Tetracycline; CIP-Ciprofloxacin; VA-Vancomycin

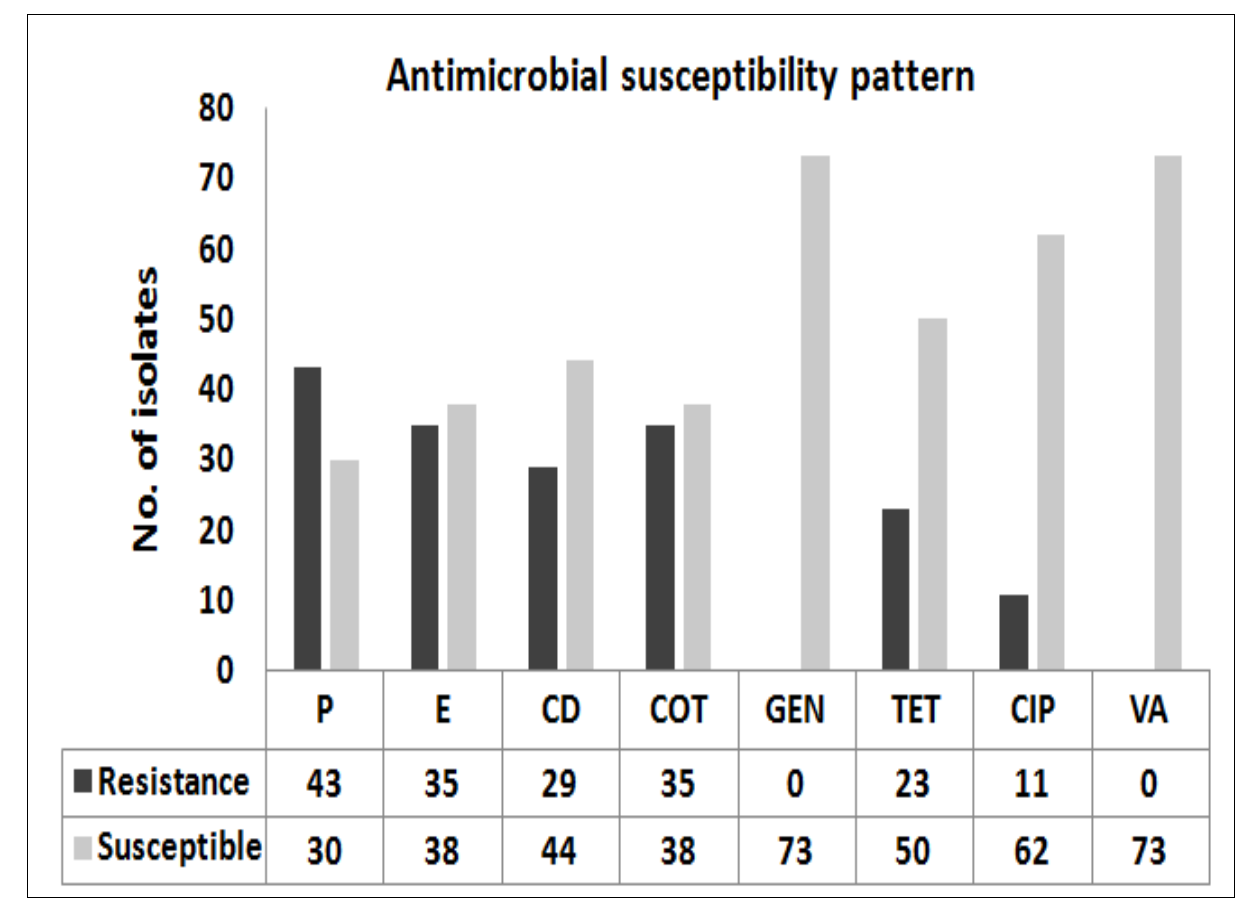

Fig.2 Representative gel picture of triplex PCR. fem A- 151bp, mec A- 293bp, pvl-450bp NC $\quad$ L1 $\quad L 2 \quad M \quad M \quad L 3 \quad L 4 \quad L 5 \quad L 6$

NC: Negative control; L1-L6: samples; M: 100bp DNA Marker 
Fig.3 Representative gel picture of ica AD (496bp)

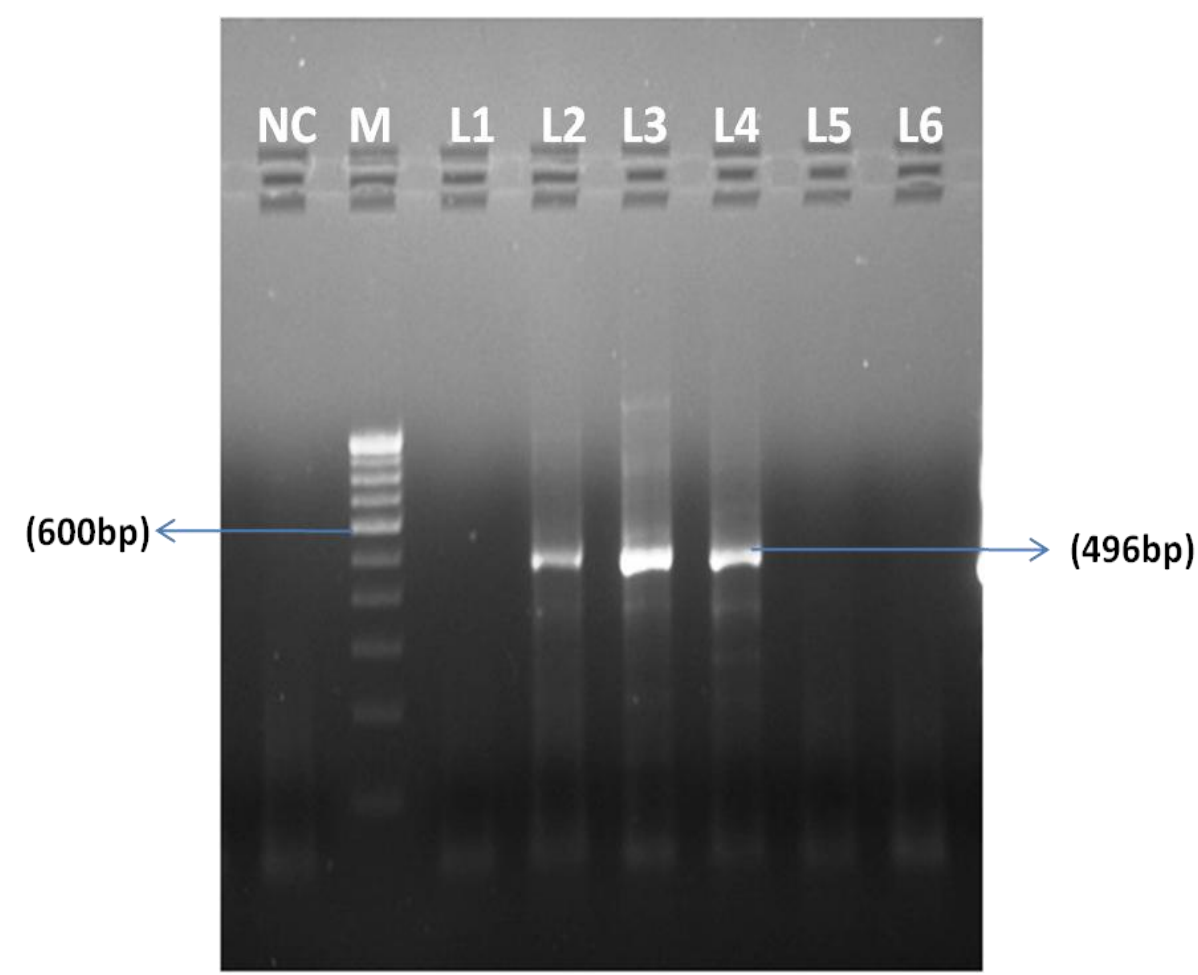

NC: Negative control; L1-L6: samples; M: 100bp DNA Marke

Global emergence of MRSA and MRCONS is serious public health problem and challenge to clinicians. A number of factors contribute to the pathogenicity and drug resistance of $S$. aureus and CONS. In the present study, highest resistance was observed for penicillin, a similar finding of penicillin resistance (87.9\%) was observed by Duran et al., 2012.

The prevalence of MRSA in human infections is quite high. In Asian countries, the prevalence rate of MRSA in hospitals has been found to be $41 \%$ in India, $42 \%$ in Pakistan, $18 \%$ in Philippines, $38 \%$ in Malaysia, $50-70 \%$ in Korea, $53-83 \%$ in Taiwan and $70 \%$ in Hong Kong and Japan (Mehndiratta and Bhalla, 2014). For the past few decades, the prevalence of MRS in Indian hospitals is continuously increasing and varies from region to region. In the present study, $36 / 49$ (73.4\%) of $S$. aureus was found to be methicillin resistant by phenotypic method and all of them were mecA positive thereby confirming the methicillin resistance. The prevalence of MR-CoNS among clinical isolates was found to be $58.3 \%$ (14/24). Previous studies from other parts of the world by Koksal et al., (2009), Garza-González et al., (2010) and Talebi et al., (2016) have reported $67.5 \%, 69 \%$ and $60 \%$ MR-CoNS respectively, which was higher than our study. In our study, S. epidermidis was the most predominant species (24.4\%) from clinical isolates followed by $S$. saprophyticus $(8.2 \%)$.

Panton-Valentine Leukocidin (PVL) appears to be epidemiologically associated with certain CA-MRSA strains. We evaluated the presence of PVL toxin as a marker for identifying the CA-MRSA isolates and found positive in 27/36 (75\%) and 9/13 (69.2\%) isolates of MRSA and MSSA respectively. Similar studies also showed the association of pvl gene in CA MRSA than HA MRSA (Eshwara, 2013; Bouchiat, 2015; Bhatta et al., 
2016). Among the ica genes, ica AD are more in $S$. aureus and CONS. Thus in the present study, these genes are screened and detected in 35/49 (71.4\%), 10/18 (55.5\%) and 3/6 $(50 \%)$ isolates of $S$. aureus, S. epidermidis and $S$. saprophyticus respectively. This finding is in contrast to other studies which showed $84.13 \%$ and $100 \%$ prevalence in $S$. aurues (Shanmugararaj et al., 2012; Salman et al., 2012).

\section{References}

Abimanyu N, Krishnan A, Murugesan S. Use of triplex PCR for rapid detection of PVL and differentiation of MRSA from methicillin resistant coagulase negative staphylococci. J. Clin. Diag. Res., 2013; 7(2): 215-18.

Araujo GL, Coelho LR, de Caravalho CB, Maciel RM, Coronado AZ, Rozenbaum R. et al., Commensal isolates of methicillin-resistant Staphylococcus epidermidis are also well equipped to produce biofilm on polystyrene surfaces. $J$ Antimicrob Chemother, 2006: (57), 855-64.

Arciola CR, Campoccia D, Speziale P, Montanaro L, Costerton JW. Biofilm formation in Staphylococcus implant infections. A review of molecular mechanisms and implications for biofilm-resistant materials. Biomaterials. 2012; 33(26): 5967-82.

Atshan SS, Nor Shamsudin M, Sekawi Z, Lung LT, Hamat RA, Karunanidhi A, et al., Prevalence of adhesion and regulation of biofilm-related genes in different clones of Staphylococcus aureus. BioMed Res. Int. 2012; 3; 55661.

Bauer AW, Kirby WM, Sherris JC, Turck M. Antibiotic Susceptibility Testing by a Standardized Single Disk Method. American J. Clin. Pathol., 45(4): 493 96.
Bhatta DR, Cavaco LM, Nath G, Kumar K, Gaur A, Gokhale S, et al., Association of Panton Valentine Leukocidin (PVL) genes with methicillin resistant Staphylococcus aureus (MRSA) in Western Nepal: a matter of concern for community infections (a hospital based prospective study). BMC Inf. Dis., 2016; 16(1): 199-202.

Bouchiat C, El-Zeenni N, Chakrakodi B, Nagaraj S, Arakere G. Epidemiology of Staphylococcus aureus in Bangalore, India: emergence of the ST217 clone and high rate of resistance to erythromycin and ciprofloxacin in the community. New Microbes New Inf., 2015; 30(7): 15-20.

CLSI. 2017. Performance Standards for Antimicrobial Susceptibility Testing; Twenty-Third Informational Supplement (CLSI Document M100S26). Clinical and Laboratory Standards Institute. Vol. 33. Wayne, PA: Clinical and Laboratory Standards Institute.

Duran N, Burcin O, Gulay GD, Yusuf O, CemilD. Antibiotic Resistance Genes \& Susceptibility Patterns in Staphylococci. The IndianJ. Medical Research 2015; 135(3): 389-96.

Eshwara VK, Munim F, Tellapragada C, Kamath A, Varma M, Lewis LE et al., Staphylococcus aureus bacteremia in an Indian tertiary care hospital: observational study on clinical epidemiology, resistance characteristics, and carriage of the Panton-Valentine leukocidin gene. International $J$. Infectious Diseases. 2013; 17(11): 1051-5.

Francois P, Pittet D, Bento M, PepeyB, Vaudaux P, Lew D, et al., Rapid detection of methicillin-resistant Staphylococcus aureus directly from sterile or nonsterile clinical samples by a new molecular assay. J. Clin. Microbiol., 2003; 41(1): 254-60. 
Garza-G, Elvira DL, Cesar P, Walter M, Virgilio BG, Ivan M, et al., Diversity of Staphylococcal Cassette Chromosome Mec Structures in Coagulase-Negative Staphylococci and Relationship to Drug Resistance. J. Medical Microbiology 2010; 59(3): 323-29.

Gowrishankar S, Kamaladevi A, Balamurugan K, Pandian SK. In Vitro and in Vivo Biofilm Characterization of Methicillin-Resistant Staphylococcus aureus from Patients Associated with Pharyngitis Infection. BioMed Res. Int., 2016:28; 156-60.

Gülmez D, Sancak B, Ercis S, Karakaya J, Hascelik G. Investigation of SCCmec types and Panton-Valentine leukocidin in community-acquired and nosocomial Staphylococcus aureus strains: comparing skin and soft tissue infections to the other infections. Mikrobiyolojibulteni. 2012; 46(3): 34151.

Hassan A, Usman J, Kaleem F, Omair M, Khalid A, Iqbal M. Evaluation of different detection methods of biofilm formation in the clinical isolates. Brazilian J. Infectious Diseases. 2011; 15(4): 305-11.

Koksal F, Yasar H, Samasti M. Antibiotic Resistance Patterns of Coagulase Negative Staphylococcus Strains Isolated from Blood Cultures of Septicemic Patients in Turkey. Microbiol. Res., 2009; 164(4): 404-10

Mehndiratta PL, Bhalla P. "Use of Antibiotics in Animal Agriculture \&Emergence of Methicillin- Resistant Staphylococcus aureus (MRSA) Clones: Need to Assess the Impact on Public Health." Indian J Med Res., 2014; 140: 339-44.

Talebi M, Mohammad S, Javad S, Nasrin AM, Mahnaz S, Mohammad RP. Genotypic Diversity of MethicillinResistant Coagulase-Negative Staphylococci Isolated from Inpatients and Outpatients. Microbial Drug Resistance, 2016; 22(2): 147-54.

\section{How to cite this article:}

Pradha Velu, Ramya Rengaraj, Usha Sekar and Saleem. 2018. Prevalence of MRSA and Biofilm Associated Gene among Clinical Isolates of Staphylococci. Int.J.Curr.Microbiol.App.Sci. 7(01): 745-752. doi: https://doi.org/10.20546/ijcmas.2018.701.090 